\title{
Association between genetic polymorphisms of cytochrome P450 2C19 and the risk of cerebral ischemic stroke in Chinese
}

\author{
Shuzhen Gu${ }^{1,2+}$, Yan Sun ${ }^{3 \dagger}$, Ruifa Han ${ }^{4}$, Lin Wang ${ }^{4}$, Dongliang Wang ${ }^{1}$, Jizuo Wang ${ }^{1}$ and Xin $\mathrm{Li}^{1^{*}}$
}

\begin{abstract}
Background: Cytochrome P450 (CYP) 2C19 is a very important drug metabolizing enzyme. Although the single nucleotide polymorphisms (SNPs) of CYP2C19 G681A and G636A have been suggested that they may increase the incidence of cardiovascular events, the relationship between SNPs in CYP2C19 and cerebral ischemic stroke (CIS) are unclear. The aim of this study was to investigate the correlation between the distribution of G681A and G636A polymorphisms in CYP2C19 gene and the risk of CIS in Chinese.

Methods: The peripheral blood DNA was extracted from 299 patients with CIS and 295 healthy controls. The genotyping was conducted using the polymerase chain reaction-restriction fragment length polymorphism. The sampled sequencing was applied to verify the correctness of genotyping results. Both the genotype and allele distributions were compared in patients with CIS and healthy controls.

Results: The frequencies of CYP2C19 681AA (11.7\% vs. 2.7\%; $P=0.000), 636 \mathrm{AA}(4.0 \%$ vs. $0.7 \% ; P=0.007), 636 \mathrm{AG}$ (7.0\% vs. 2.2\%; $P=0.038$ ) genotype, CYP2C19 681A (30.9\% vs. 20.8\%; $P=0.000)$ and 636A $(13.0 \%$ vs. $5.8 \% ; P=0.000)$ allele in the CIS group are significantly higher than those in the controls. The frequencies of CYP2C19 681AA (16.7\% vs. 8.6\%; $P=0.036$ ), CYP2C19 636AA (7.0\% vs. 2.2\%; $P=0.038$ ) genotype, CYP2C19 681A (36.4\% vs. 27.6\%; $P=0.023$ ) and CYP2C19 636A (17.5\% vs.10.3\%; $P=0.010)$ allele in the recurrent stroke group are significantly higher than those in the first onset group. Multivariate logistic regression analysis of risk factors for cerebral ischemic stroke and recurrent stroke respectively suggests that the CYP2C19 681AA genotype may be an independent risk factor for CIS (OR $=6.179$, 95\% Cl: $2.285 \sim 16.708 ; P=0.000)$ and recurrent stroke $(\mathrm{OR}=2.305,95 \% \mathrm{Cl}: 1.121 \sim 4.743 ; P=0.023)$.
\end{abstract}

Conclusions: The AA genotype and A allele of CYP2C19 G681A may be related to the occurrence and recurrence of cerebral ischemic stroke.

Keywords: Cerebral ischemic stroke, CYP2C19, Genetic polymorphism

\section{Background}

The occurrence of cerebral ischemic stroke is influenced by eating habits, environment, genetic factors and so on. Fundamentally, genetic factors involve in a series of key enzymes and receptors on many metabolic pathways. Therefore, the study of the genetic risk factor for cerebral ischemic stroke has become a hot spot currently.

Cytochrome P450(CYP) 2C19 is a very important drug metabolizing enzyme, which involves in approximately $2 \%$

\footnotetext{
* Correspondence: lixinsci@126.com

${ }^{\dagger}$ Equal contributors

'Department of Neurology, the Second Hospital of Tianjin Medical University, Tianjin 300211, China

Full list of author information is available at the end of the article
}

of the clinical drug metabolism. The activity of CYP2C19 enzyme not only exhibits a significant ethnic heterogeneity, but also has an obvious differences between individuals. It is believed that the differences are mainly caused by genetic variations. Many researchers have investigated the molecular mechanism of CYP2C19 enzyme polymorphisms, which include the wild-type CYP2C19*1, CYP2C19*2, CYP2C19*3, CYP2C19*4, CYP2C19*5, CY P2C19*6, CYP2C19*7, CYP2C19*8, etc. CYP2C19*2 and CYP2C19*3 are the main variants in CYP2C19, while others are relatively rare in humans.

Studies have shown that the single nucleotide polymorphisms (SNPs) of CYP2C19*2(CYP2C19 G681A, rs4244285)

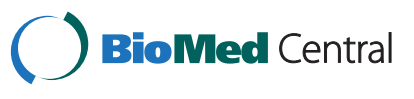

(C) 2014 Gu et al.; licensee BioMed Central Ltd. This is an Open Access article distributed under the terms of the Creative Commons Attribution License (http://creativecommons.org/licenses/by/2.0), which permits unrestricted use, distribution, and reproduction in any medium, provided the original work is properly credited. The Creative Commons Public Domain Dedication waiver (http://creativecommons.org/publicdomain/zero/1.0/) applies to the data made available in this article, unless otherwise stated. 
and CYP2C19*3(CYP2C19 G636A, rs4986893) may increase the incidence of cardiovascular events [1-3]. Whereas there are less research about the relationship between SNPs in CYP2C19 and cerebral ischemic stroke. So we carried out a case-control study to investigate the relationship between the distribution of G681A and G636A polymorphisms in CYP2C19 gene and cerebral ischemic stroke in Chinese Han population.

\section{Methods \\ Study participants}

From May 2011 to March 2013, we recruited 299 patients with acute cerebral ischemic stroke who were admitted to the Neurology Department of the second hospital, Tianjin Medical University, Tianjin, China. All patients were diagnosed as acute cerebral ischemic stroke, which was diagnosed by a neurologist according to the diagnostic criteria determined by the guidelines for the primary prevention of stroke: a guideline for healthcare professionals from the American Heart Association/American Stroke Association [4] and confirmed by computed tomographic (CT) scan and/or conventional magnetic resonance imaging (MRI) of the brain; the time from incidence to hospitalization was less than seven days. We excluded patients who had cerebral hemorrhage, transient ischemic attack (TIA), cerebral venous thrombosis, nervous system infection, neurodegenerative disease, hepatic and renal dysfunction, thrombocytopenia and tumor. In addition, patients were excluded when they took PPI, tricyclic antidepressants, antiepileptics and antipsychotics.

Controls enrolled in this study may have high blood pressure, diabetes, smoking and other vascular risk factors, excluding history of cerebral ischemic stroke, TIA, atrial fibrillation, myocardial infarction and venous thrombosis.

All subjects were unrelated Chinese Han. There were no significant differences in the age and sex distributions. Informed consent was obtained from all subjects, and the study was approved by the Ethical Committee of Tianjin Medical University.

\section{Data collection}

All subjects underwent a comprehensive medical history, physical examination and clinical chemistry analysis before enrollment. Diagnosis of hyperlipidemia was based on China's adult dyslipidemia prevention guide [5]. Hypertension was defined as a blood pressure greater than 140/ $90 \mathrm{mmHg}$ on at least two independent readings, exclude secondary hypertension. Diagnosis of ischemic heart disease according to the WHO diagnostic criteria [6]. Diagnosis of diabetes mellitus according to the WHO diagnostic criteria [7], exclude type 1 diabetes mellitus and secondary diabetes.

\section{Genotyping}

Blood samples were collected in tubes containing EDTA. The genomic DNA was extracted using a commercially available DNA isolation kit (Cwbiotech, Beijing, China) according to the manufacturer's instruction.

The primers of CYP2C19*2 and CYP2C19*3 alleles were designed and synthesized by BGI Beijing Corporation. The forward primer of $5^{\prime}$ - ACC AGA GCT TGG CAT ATT GTA TCT $-3^{\prime}$ and the reverse primer of $5^{\prime}$-GAT TCT TGG TGT TCT TTT ACT TTC T-3' were used for the amplification of the CYP2C19*2 allele. For the CYP2C 19*3 variant, the forward primer was 5 ' - TTT CAT CCT GGG CTG TGC TC $-3^{\prime}$ and the reverse primer was 5'- TGT ACT TCA GGG CTT GGT CAA T -3'. The PCR was performed with an initial denaturation at $94^{\circ} \mathrm{C}$ for $5 \mathrm{~min}$, followed by 35 cycles of denaturation at $94^{\circ} \mathrm{C}$ for $30 \mathrm{~s}$, annealing at $60^{\circ} \mathrm{C}$ for $30 \mathrm{~s}$, elongation at $72^{\circ} \mathrm{C}$ for $30 \mathrm{~s}$, and a final extension at $72^{\circ} \mathrm{C}$ for $10 \mathrm{~min}$. The amplified products of CYP2C19*2 (192bp) and CYP2C19*3 (234bp) were respectively digested with SmaI and BamHI fastdigest restriction enzyme (Takara biotechnology, Dalian).

Samples from each genotype of CYP2C19 were selected randomly and submitted for direct DNA sequencing which confirmed the results.

\section{Statistical analysis}

Continuous variables were expressed as mean \pm standard deviation (SD) and categorical variables were reported as counts and percentages. Analyses of t-tests and chi-square tests were used to test for differences between groups for continuous and categorical variables, respectively. Multivariate logistic regression analysis was used to identify independent predictors of cerebral ischemic stroke. Analyses were performed using SPSS version 19.0 statistical software. A value of $\mathrm{P}<0.05$ (two-sided) was considered statistically significant. The $\mathrm{p}$ value is accurate to three decimal places when we calculated using SPSS.

\section{Results}

A total of 299 patients were enrolled in this study, including 177 cases of male, 122 cases of female, the first onset group were 185 cases, the recurrent stroke group were 114 cases, the mean ages were $(67.86 \pm 11.472)$ years. And a total of 295 controls were enrolled, including 159 males, 136 females, the mean ages were $(66.45 \pm 12.972)$ years.

\section{Genotyping}

The PCR products of CYP2C19*2 and CYP2C19*3 were respectively $192 \mathrm{bp}$ and $234 \mathrm{bp}$, which were shown in Figure 1A, and their digested products were respectively showed in Figure $1 \mathrm{~B}$ and Figure $1 \mathrm{C}$.

As shown in Figure 2, the results of direct DNA sequencing verified the correctness of genotyping results. 


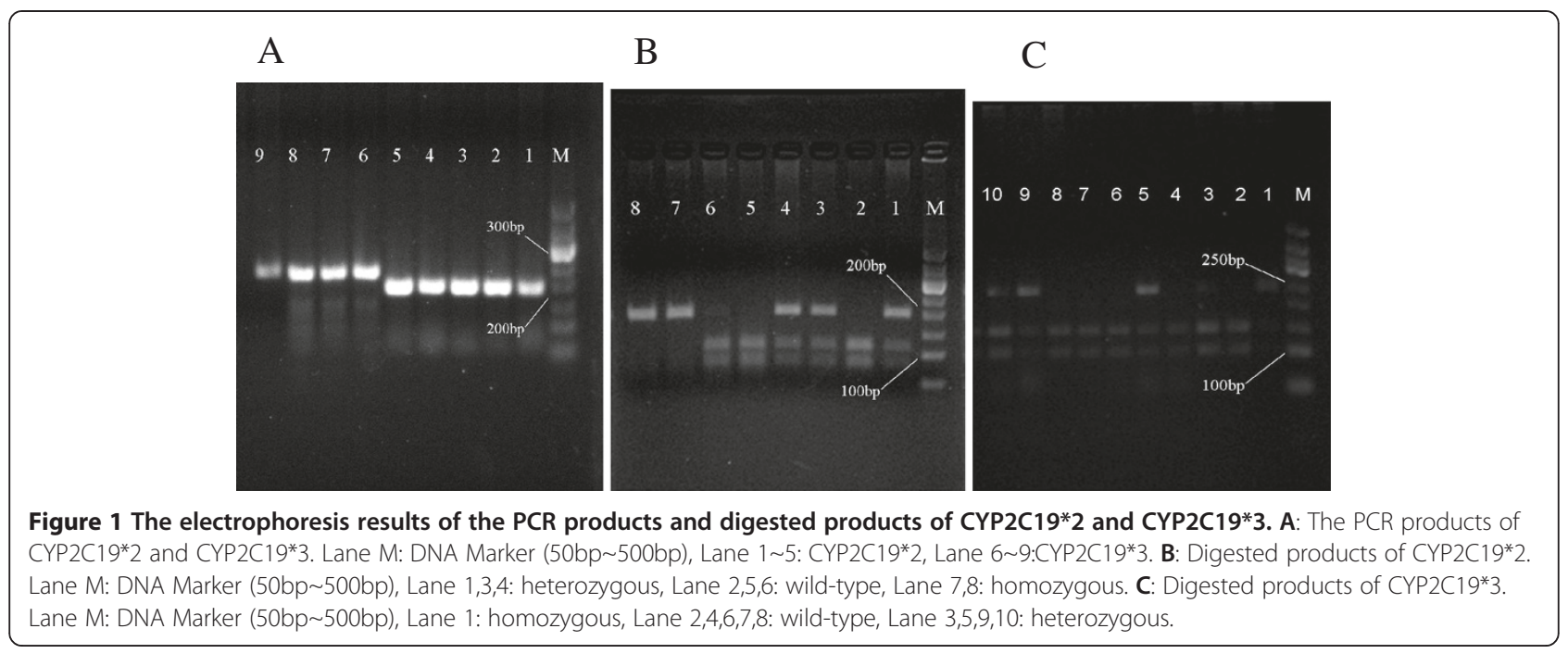

\section{Clinical characteristics}

Baseline clinical characteristics of the cerebral ischemic stroke group and the control group are shown in Table 1. The proportions of hypertension, diabetes, ischemic heart disease, hyperlipidemia, smoking and drinking in the cerebral ischemic stroke group were more than those in the healthy control group. And the levels of fasting bloodglucose (FBG), systolic blood pressure and diastolic blood pressure were significantly higher in the cerebral ischemic stroke than in the control group, while the level of high-density lipoprotein cholesterol (HDL-C) was significantly lower in the cerebral ischemic stroke than in the control group. As shown in Table 1, there were also no significant differences in the levels of total cholesterol (TC), triglyceride (TG) and LDL-C.

Meanwhile, there were no significant differences in the proportions of age, gender, smoking, drinking, hypertension, diabetes, ischemic heart disease, myocardial infarction and hyperlipidemia in the recurrent stroke group and the first onset group. There were no significant differences in

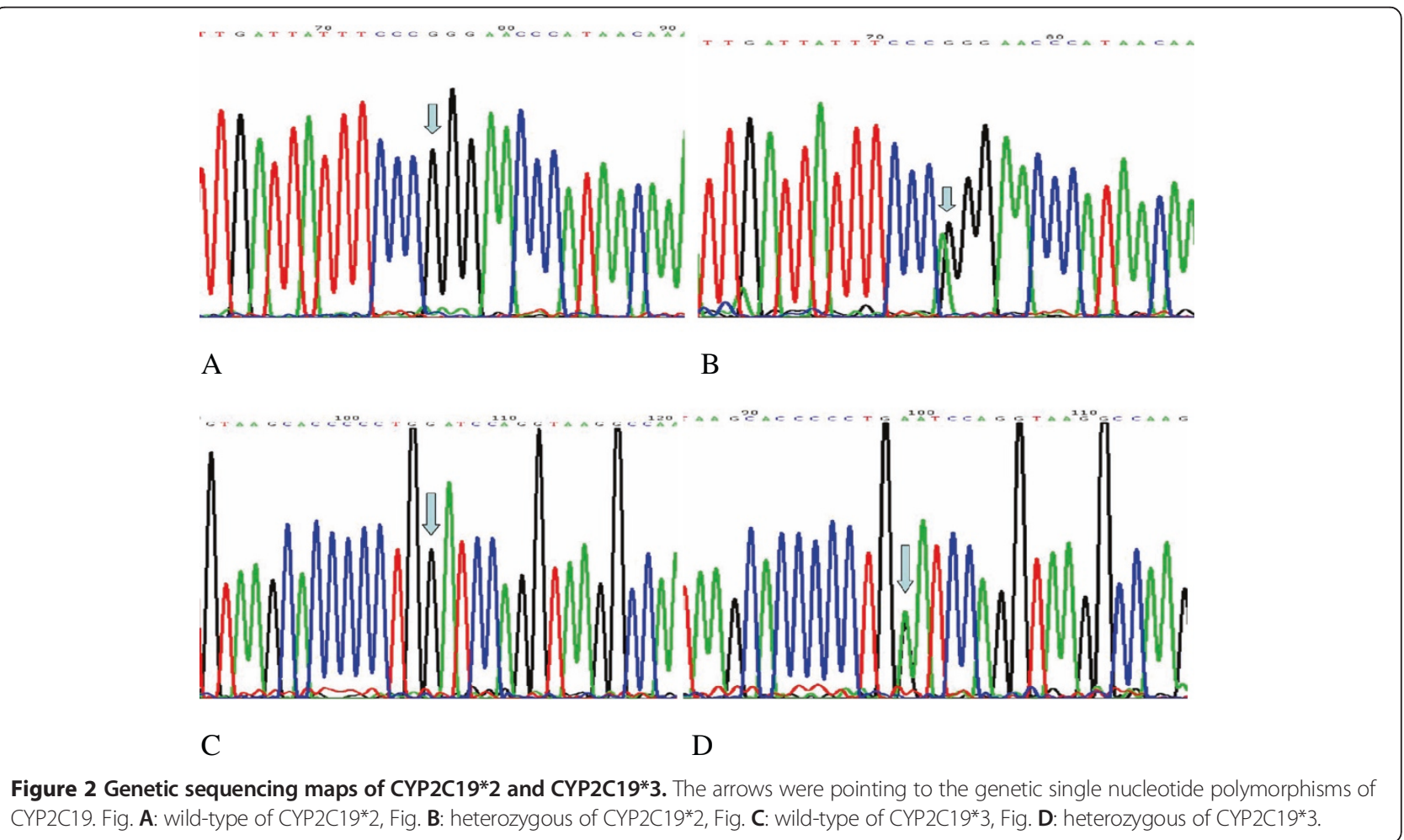


Table 1 Demographic and clinical information of the cerebral ischemic stroke and the control group

\begin{tabular}{|c|c|c|c|c|}
\hline Variable & The cerebral ischemic stroke $(n=299)$ & The control group $(n=295)$ & $\mathrm{t} / \mathrm{X}^{2}$ value & $P$ value \\
\hline Age (years) & $67.86 \pm 11.472$ & $66.45 \pm 12.972$ & 1.381 & 0.168 \\
\hline Male $(n, \%)$ & $177(59.2)$ & $159(53.9)$ & 1.697 & 0.193 \\
\hline Hypertension (n, \%) & $225(75.3)$ & $75(25.4)$ & 147.483 & 0.000 \\
\hline Diabetes (n, \%) & $103(34.4)$ & $21(7.1)$ & 67.147 & 0.000 \\
\hline Hyperlipidemia (n, \%) & $161(53.8)$ & $122(41.4)$ & 9.287 & 0.002 \\
\hline Ischemic heart disease $(n, \%)$ & $106(35.5)$ & $36(12.2)$ & 44.119 & 0.000 \\
\hline Smoking ( $n, \%)$ & $119(39.8)$ & $31(10.5)$ & 67.495 & 0.000 \\
\hline Drinking (n, \%) & $72(24.1)$ & $20(6.8)$ & 33.956 & 0.000 \\
\hline Systolic blood pressure $(\mathrm{mmHg})$ & $153.01 \pm 22.593$ & $127.82 \pm 18.146$ & 14.971 & 0.000 \\
\hline Diastolic blood pressure $(\mathrm{mmHg})$ & $86.21 \pm 12.644$ & $76.51 \pm 9.684$ & 10.489 & 0.000 \\
\hline Total cholesterol (mmol/L) & $5.033 \pm 1.366$ & $5.211 \pm 1.030$ & -1.791 & 0.074 \\
\hline Triglyceride (mmol/L) & $1.654 \pm 1.116$ & $1.537 \pm 1.038$ & 1.322 & 0.187 \\
\hline High-density lipoprotein cholesterol (mmol/L) & $1.113 \pm 0.562$ & $1.316 \pm 0.452$ & -4.842 & 0.000 \\
\hline Low-density lipoprotein cholesterol (mmol/L) & $3.157 \pm 1.061$ & $3.078 \pm 0.815$ & 1.028 & 0.304 \\
\hline Fasting blood-glucose (mmol/L) & $7.504 \pm 3.461$ & $5.538 \pm 0.980$ & 9.391 & 0.000 \\
\hline
\end{tabular}

Continuous variables were expressed as mean \pm standard deviation (SD) and categorical variables were reported as counts and percentages. The blood pressure is measured in millimetres of mercury $(\mathrm{mm} \mathrm{Hg})$. The blood lipids and glucose concentrations are record in milimolar per litre ( $\mathrm{mmol} / \mathrm{L})$.

the levels of baseline blood pressure, TC, TG, high-density lipoprotein cholesterol (HDL-C) and FBG in the two groups, which were shown in Table 2.

\section{Frequency of CYP2C19 genotypes and alleles}

The frequency of the major and minor alleles of CYP2C19*2 and CYP2C19*3 did not deviate significantly from the Hardy-Weinberg equilibrium neither in the stroke ( $\left.\mathrm{X}^{2}=1.380, P=0.502 ; \mathrm{X} 2=4.180, P=0.124\right)$, nor in the control group $\left(\chi^{2}=1.749, P=0.417 ; \chi^{2}=0.400\right.$, $P=0.819$ ). Frequencies of the CYP2C19*2 and CYP2C19*3 polymorphism in cerebral ischemic stroke patients and healthy controls are described in Table 3. Frequencies of CYP2C19 681AA (30.9\% vs. 20.8\%; $P=0.000)$, CYP2C19 636AA (4.0\% vs. $0.7 \% ; P=0.007)$, CYP2C19 636AG (18.1\% vs. $10.2 \% ; P=0.006)$ genotype, CYP2C19 681A (30.9\% vs.

Table 2 Demographic and clinical information of the recurrent stroke group and the first onset group

\begin{tabular}{|c|c|c|c|c|}
\hline Variable & The recurrent stroke group $(n=114)$ & The first onset group $(n=185)$ & $t / x^{2}$ value & $P$ value \\
\hline Age (years, mean $\pm S D$ ) & $69.37 \pm 11.132$ & $68.28 \pm 11.149$ & 0.801 & 0.424 \\
\hline Male (n, \%) & $62(54.4)$ & $115(62.2)$ & 1.766 & 0.184 \\
\hline Hyperlipidemia (n, \%) & $87(76.3)$ & 138(74.6) & 0.180 & 0.672 \\
\hline Diabetes (n, \%) & $42(36.8)$ & $61(33.0)$ & 0.468 & 0.494 \\
\hline Hyperlipidemia (n, \%) & $65(57.0)$ & $96(51.9)$ & 0.746 & 0.388 \\
\hline Ischemic heart disease (n, \%) & $48(42.1)$ & $58(31.4)$ & 3.565 & 0.059 \\
\hline myocardial infarction (n, \%) & $4(3.5)$ & $12(6.5)$ & 1.235 & 0.266 \\
\hline Smoking (n, \%) & $40(35.1)$ & $79(42.7)$ & 1.707 & 0.191 \\
\hline Drinking (n, \%) & 23(20.2) & $49(26.5)$ & 1.537 & 0.215 \\
\hline Systolic blood pressure $(\mathrm{mmHg}$, mean $\pm \mathrm{SD})$ & $150.99 \pm 23.368$ & $154.26 \pm 22.074$ & -1.216 & 0.225 \\
\hline Diastolic blood pressure $(\mathrm{mmHg}$, mean $\pm \mathrm{SD})$ & $85.82 \pm 11.937$ & $86.46 \pm 13.086$ & -0.427 & 0.670 \\
\hline Total cholesterol $(\mathrm{mmol} / \mathrm{L}$, mean $\pm \mathrm{SD})$ & $4.990 \pm 1.619$ & $5.059 \pm 1.188$ & -0.427 & 0.670 \\
\hline Triglyceride $(\mathrm{mmol} / \mathrm{L}$, mean $\pm \mathrm{SD})$ & $1.567 \pm 0.938$ & $1.708 \pm 1.212$ & -1.062 & 0.289 \\
\hline $\begin{array}{l}\text { High-density lipoprotein cholesterol } \\
\qquad(\mathrm{mmol} / \mathrm{L} \text {, mean } \pm \mathrm{SD})\end{array}$ & $1.056 \pm 0.303$ & $1.148 \pm 0.672$ & -1.386 & 0.167 \\
\hline $\begin{array}{l}\text { Low-density lipoprotein cholesterol } \\
\quad(\mathrm{mmol} / \mathrm{L}, \text { mean } \pm \mathrm{SD})\end{array}$ & $3.148 \pm 1.325$ & $3.163 \pm 0.862$ & -0.119 & 0.905 \\
\hline Fasting blood-glucose $(\mathrm{mmol} / \mathrm{L}$, mean $\pm \mathrm{SD})$ & $7.733 \pm 3.798$ & $7.363 \pm 3.239$ & 0.898 & 0.370 \\
\hline
\end{tabular}


Table 3 Frequencies of the CYP2C19 polymorphism in cerebral ischemic stroke patients and healthy controls ( $\mathrm{n}$, \%)

\begin{tabular}{|c|c|c|c|c|c|c|c|c|c|c|}
\hline \multirow{2}{*}{ Groups } & \multicolumn{3}{|c|}{ CYP2C19*2 genotypes } & \multicolumn{2}{|c|}{ CYP2C19*2 alleles } & \multicolumn{3}{|c|}{ CYP2C19*3 genotypes } & \multicolumn{2}{|c|}{ CYP2C19*3 alleles } \\
\hline & AA & AG & GG & A & G & AA & AG & GG & A & G \\
\hline Stroke & 35 & 115 & 149 & 185 & 413 & 12 & 54 & 233 & 78 & 520 \\
\hline$(n=299)$ & $(11.7)$ & $(38.5)$ & $(49.8)$ & $(30.9)$ & $(69.1)$ & $(4.0)$ & $(18.1)$ & $(77.9)$ & $(13.0)$ & $(87.0)$ \\
\hline Control & 8 & 107 & 180 & 123 & 467 & 2 & 30 & 263 & 34 & 556 \\
\hline$(n=295)$ & (2.7) & $(36.3)$ & $(61.0)$ & $(20.8)$ & $(79.2)$ & $(0.7)$ & $(10.2)$ & $(89.2)$ & (5.8) & $(94.2)$ \\
\hline x2 value & 17.887 & 0.304 & 7.517 & \multicolumn{2}{|c|}{15.741} & 7.178 & 7.615 & 13.584 & \multicolumn{2}{|c|}{18.437} \\
\hline$P$ value & 0.000 & 0.581 & 0.006 & \multicolumn{2}{|c|}{0.000} & 0.007 & 0.006 & 0.000 & \multicolumn{2}{|c|}{0.000} \\
\hline
\end{tabular}

20.8\%; $P=0.000)$ and CYP2C19 636A (13.0\% vs. 5.8\%; $P=0.000)$ allele were significantly higher in the cerebral ischemic stroke than in the control group.

Frequencies of the CYP2C19*2 and CYP2C19*3 polymorphisms in recurrent stroke group and the first onset group are described in Table 4. Frequencies of CYP2C19 681AA (16.7\% vs. 8.6\%; $P=0.036)$, CYP2C19 636AA (7.0\% vs. $2.2 \% ; P=0.038)$ genotype, CYP2C19 681A $(36.4 \%$ vs. $27.6 \% ; P=0.023)$ and CYP2C19 636A (17.5\% vs. $10.3 \%$; $P=0.010$ ) allele were significantly higher in recurrent stroke group than in the first onset group.

Neurological functions were evaluated immediately with the US National Institutes of Health nerve function deficit score (NIHSS) after admission to hospital. Patients were divided into mild $(\mathrm{NIHSS}<5)$, moderate $(5 \leq \mathrm{NIHSS} \leq 20)$ and severe (NIHSS $>20)$ by rating results [8]. As shown in Table 5, no significant differences were found in genotype ( $\left.X^{2}=4.967, P=0.291 ; X^{2}=3.239, P=0.519\right)$ and allele ( $\left.\chi^{2}=0.616, P=0.735 ; X^{2}=1.242, P=0.537\right)$ frequencies of CYP2C19*2 and CYP2C19*3 in the three groups.

\section{Correlation between CYP2C19 genetic polymorphisms and cerebral ischemic stroke}

Multivariate logistic regression analysis showed that the CYP2C19 681AA genotype was an independent risk factor for cerebral ischemic stroke (odds ratio (OR) 6.179, 95\% confidence interval (CI) $2.285 \sim 16.708 ; P=0.000$ ), which were shown in Table 6, and the CYP2C19 681 AA genotype was an independent risk factor for recurrent stroke (OR 2.305, 95\% CI $1.121 \sim 4.743 ; P=0.023$ ), while
CYP2C19 636 AA genotype was not associated with the recurrence of ischemic stroke $(P=0.098)$. Meanwhile, as shown in Table 6, hypertension was an independent risk factor for cerebral ischemic stroke (OR 2.998, 95\% CI $1.808 \sim 4.972 ; P=0.000)$.

\section{Discussion}

CYP2C19 is located within a cluster of cytochrome P450 genes on chromosome 10q24, which contains nine exons and eight introns. The gene encodes a 490-aa long protein of approximately $56 \mathrm{kDa}$, which is a member of the cytochrome P450 superfamily of enzymes. This protein localizes to the endoplasmic reticulum and is known to metabolize many xenobiotics, including the anticonvulsive drug mephenytoin, omeprazole, diazepam and some barbiturates. Polymorphism within this gene is associated with variable ability to metabolize mephenytoin, known as the poor metabolizer and extensive metabolizer phenotypes. CYP2C19*2 has been shown to be a $\mathrm{G} \rightarrow \mathrm{A}$ transition at $681 \mathrm{bp}$ in exon 5 of wild-type CYP2C19*1. This variant results in an aberrant splice site and shifts the reading frame, thereby producing an early-stop codon and a truncated protein [9]. The CYP2C19*3 involves a $\mathrm{G} \rightarrow \mathrm{A}$ variant at 636bp in exon 4 , that also creates a premature stop codon and a truncated protein [10]. The CYP2C19*2 is the main genetic defect allele of CYP2C19, which accounts for $75 \% \sim 85 \%$ of poor metabolizers (PM) in both white and Oriental populations [11]. The second variant accounts for the remaining defective alleles in Oriental

Table 4 Frequencies of the CYP2C19 polymorphism in recurrent stroke group and the first onset group (n, \%)

\begin{tabular}{|c|c|c|c|c|c|c|c|c|c|c|}
\hline \multirow{2}{*}{ Groups } & \multicolumn{3}{|c|}{ CYP2C19*2 genotypes } & \multicolumn{2}{|c|}{ CYP2C19*2 alleles } & \multicolumn{3}{|c|}{ CYP2C19*3 genotypes } & \multicolumn{2}{|c|}{ CYP2C19*3 alleles } \\
\hline & AA & AG & GG & A & G & AA & AG & GG & A & G \\
\hline The recurrent stroke group & 19 & 45 & 50 & 83 & 145 & 8 & 24 & 82 & 40 & 188 \\
\hline$(n=114)$ & $(16.7)$ & $(39.5)$ & $(43.9)$ & $(36.4)$ & $(63.6)$ & $(7.0)$ & $(21.1)$ & $(71.9)$ & $(17.5)$ & $(82.5)$ \\
\hline The first onset group & 16 & 70 & 99 & 102 & 268 & 4 & 30 & 151 & 38 & 332 \\
\hline$(n=185)$ & (8.6) & $(37.8)$ & $(53.5)$ & $(27.6)$ & $(72.4)$ & $(2.2)$ & $(16.2)$ & $(81.6)$ & $(10.3)$ & $(89.7)$ \\
\hline$x^{2}$ value & 4.387 & 0.080 & 2.629 & \multicolumn{2}{|c|}{5.155} & 4.316 & 1.115 & 3.852 & \multicolumn{2}{|c|}{6.580} \\
\hline$P$ value & 0.036 & 0.778 & 0.105 & \multicolumn{2}{|c|}{0.023} & 0.038 & 0.291 & 0.050 & \multicolumn{2}{|c|}{0.010} \\
\hline
\end{tabular}


Table 5 Frequencies of the CYP2C19 polymorphism in different NIHSS groups in patients

\begin{tabular}{|c|c|c|c|c|c|c|c|c|c|c|}
\hline \multirow[t]{2}{*}{ Groups } & \multicolumn{3}{|c|}{ CYP2C19*2 genotypes } & \multicolumn{2}{|c|}{ CYP2C19*2 alleles } & \multicolumn{3}{|c|}{ CYP2C19*3 genotypes } & \multicolumn{2}{|c|}{ CYP2C19*3 alleles } \\
\hline & AA & AG & GG & A & & AA & AG & GG & A & G \\
\hline Mild & 19 & 64 & 78 & 102 & 220 & 6 & 34 & 121 & 46 & 276 \\
\hline$(n=161)$ & $(11.8)$ & (39.8) & $(48.4)$ & $(31.7)$ & $(68.3)$ & $(3.7)$ & $(21.1)$ & $(75.2)$ & $(14.3)$ & $(85.7)$ \\
\hline Moderate & 8 & 37 & 39 & 53 & 115 & 4 & 10 & 70 & 18 & 150 \\
\hline$(n=84)$ & (9.5) & $(44.0)$ & $(46.4)$ & $(31.5)$ & $(68.5)$ & $(4.8)$ & $(11.9)$ & $(83.3)$ & $(10.7)$ & (89.3) \\
\hline Severe & 8 & 14 & 32 & 30 & 78 & 2 & 10 & 42 & 14 & 94 \\
\hline$(n=54)$ & $(14.8)$ & $(25.9)$ & $(59.3)$ & $(27.8)$ & $(72.2)$ & (3.7) & $(18.5)$ & $(77.8)$ & $(13.0)$ & $(87.0)$ \\
\hline$x^{2}$ value & 0.893 & 4.806 & 2.432 & \multicolumn{2}{|c|}{0.616} & 0.170 & 3.176 & 2.147 & \multicolumn{2}{|c|}{1.242} \\
\hline$P$ value & 0.640 & 0.090 & 0.296 & \multicolumn{2}{|c|}{0.735} & 0.919 & 0.204 & 0.342 & \multicolumn{2}{|c|}{0.537} \\
\hline
\end{tabular}

populations PM, but appears to be extremely rare in white persons [12].

Yin et al. [13] found that the allele frequencies of CYP2C19*2 were respectively $29.7 \%, 32.4 \%$ and $18.2 \%$ in Han, Hui and Mongolian, the allele frequencies of CYP2C19*3 were respectively $7.9 \%, 10.2 \%$ and $11.2 \%$ in Han, Hui and Mongolian. Other literatures [14,15] reported that the allele frequencies of CYP2C19*2 were $11.1 \%$ for Western Africa, 14.0\% for Western Europe and 16.3\% for Northern Europe respectively, and the allele frequencies of CYP2C19*3 were 0\% for Western Africa, 0.2\% for Western Europe and $0.2 \%$ for Northern Europe respectively. In our study, the allele frequencies of CYP2C19*2 and CYP2C19*3 were $25.9 \%$ and $9.4 \%$ separately. Our result is close with that in Yin's report.

Studies have shown that the poor metabolizer gene of CYP2C19 was related to the occurrence of coronary heart disease and stroke. Through the research of 654 patients with coronary heart disease, Mao Chen et al. [16] found that the homozygous CYP2C19*2/"2 genotype was an independent determinant of adverse vascular events in Chinese patients with coronary artery disease (CAD). Mega et al. [17] reported that carriers of a reduced-function CYP2C19 allele had a higher rate of major adverse cardiovascular events than did noncarriers. Actually our research

Table 6 Multivariate logistic regression analysis of independent risk factor for cerebral ischemic stroke

\begin{tabular}{cccc}
\hline Independent risk factor & $\mathbf{9 5 \%} \mathbf{~ C l}$ & P value & OR value \\
\hline CYP2C19 681AA & $2.285 \sim 16.708$ & 0.000 & 6.179 \\
Hypertension & $1.808 \sim 4.972$ & 0.000 & 2.998 \\
Ischemic heart disease & $1.366 \sim 4.210$ & 0.002 & 2.398 \\
Diabetes & $1.262 \sim 4.838$ & 0.008 & 2.471 \\
Hyperlipidaemia & $1.086 \sim 3.120$ & 0.023 & 1.841 \\
Smoking & $3.712 \sim 11.816$ & 0.000 & 6.623 \\
Systolic blood pressure & $1.036 \sim 1.065$ & 0.000 & 1.051 \\
TC & $0.626 \sim 0.924$ & 0.006 & 0.761 \\
FBG & $1.257 \sim 1.742$ & 0.000 & 1.480 \\
\hline
\end{tabular}

also found that CYP2C19 681AA genotype, CYP2C19 636AA and CYP2C19 636AG genotype were related with cerebral ischemic stroke. Multivariate logistic regression analysis showed that the CYP2C19 681AA genotype may be an independent risk factor for cerebral ischemic stroke. We postulate that the weak metabolic gene of CYP2C19 may be related to the formation of cerebral artery atherosclerosis, thereby causing the incidence of cerebral ischemic stroke.

Clopidogrel is a prodrug requiring metabolism by CYP2C19 enzyme, in order to be active, which can play the role of anti-platelet aggregation. Clopidogrel is widely used in the secondary prevention of cerebral ischemic stroke, but its clinical efficacy has individual differences. Many studies have shown that CYP2C19 polymorphism is associated with reduced clopidogrel response [18-23]. Our study suggested that the CYP2C19 681AA genotype was an independent risk factor for recurrent stroke, since carriers of a reduced-function CYP2C19 allele had a twofold risk with recurrent stroke than did noncarriers.

\section{Conclusion}

In summary, the AA genotype and A allele of CYP2C19 G681A may be associated with the occurrence and recurrence of cerebral ischemic stroke. In addition, we find that the genotypes of CYP2C19 G681A and G636A have nothing to do with the severity of cerebral ischemic stroke. Since our study has limited sample size, further studies in a large population are needed to confirm these findings.

\footnotetext{
Abbreviations

CYP: Cytochrome P450; CIS: Cerebral ischemic stroke; SNPs: Single nucleotide polymorphisms; CT: Computed tomographic; MRI: Magnetic resonance imaging; TIA: Transient ischemic attack; SD: Standard deviation; FBG: Fasting blood-glucose; HDL-C: High-density lipoprotein cholesterol; TC: Total cholesterol; TG: Triglyceride; OR: Odds ratio; Cl: Confidence interval.

Competing interests

The authors declare that they have no competing interests.

Authors' contributions

LX applied the grants and designed the proposal. GS carried out the laboratory work, analyzed the data and drafted the manuscript. SY guided
} 
the molecular biology experiments and revised the manuscript. Before submission each author have read and given final approval of the manuscript. All authors read and approved the final manuscript.

\section{Acknowledgments}

This work was supported by the applied basic research programs and cutting-edge technology of Tianjin, China (09JCYBJC11400), the science and technology program of Tianjin, China (12ZCZDSY03100), the education social science key program Tianjin, China (2011ZD016).

\section{Author details}

'Department of Neurology, the Second Hospital of Tianjin Medical University, Tianjin 300211, China. ²Department of Electromyography, Luoyang Central Hospital affiliated to Zhengzhou University, Luoyang 471009, China. ${ }^{3}$ Tianjin Institute of Urology, the Second Hospital of Tianjin Medical University, Tianjin 300211, China. ${ }^{4}$ Department of Gerontology, the Second Hospital of Tianjin Medical University, Tianjin 300211, China.

Received: 27 October 2013 Accepted: 9 July 2014

Published: 17 July 2014

\section{References}

1. Jang JS, Cho Kl, Jin HY, Seo JS, Yang TH, Kim DK, Kim DS, Seol SH, Kim DI, Kim BH, Park YH, Je HG, Jeong YH, Lee SW: Meta-analysis of cytochrome P450 2C19 polymorphism and risk of adverse clinical outcomes among coronary artery disease patients of different ethnic groups treated with clopidogrel. Am J Cardiol 2012, 110(4):502-508.

2. Yamamoto K, Hokimoto S, Chitose T, Morita K, Ono T, Kaikita K, Tsujita K, Abe T, Deguchi M, Miyagawa H, Saruwatari J, Sumida H, Sugiyama S, Nakagawa K: Impact of CYP2C19 polymorphism on residual platelet reactivity in patients with coronary heart disease during antiplatelet therapy. J Cardiol 2011, 57(2):194-201.

3. Simon T, Verstuyft C, Mary-Krause M, Quteineh L, Drouet E, Meneveau N, Steg G, Ferrieres J, Danchin N, Becquemont L: Genetic determinants of response to clopidogrel and cardiovascular events. N Engl J Med 2009, 360:363-375.

4. Goldstein LB, Bushnell CD, Adams RJ, Appel $\amalg$, Braun LT, Chaturvedi $S$, Creager MA, Culebras A, Eckel RH, Hart RG, Hinchey JA, Howard VJ, Jauch EC, Levine SR, Meschia JF, Moore WS, Nixon JV, Pearson TA: Guidelines for the primary prevention of stroke: a guideline for healthcare professionals from the American Heart Association/American Stroke Association. Stroke 2011, 42(2):517-584.

5. Chinese adult dyslipidemia prevention guidelines establish joint committee: Chinese adult dyslipidemia prevention guidelines. Chin J Cardiol 2007, 35:390-419. in Chinese.

6. Joint report of the International Society of Cardiology Association/World Health Organization clinical named standardized thematic group: The naming and standards of the diagnosis of ischemic heart disease. Intern J Cardiol 1979, 6:365-366. in Chinese.

7. World Health Organization: Definition and diagnosis of diabetes mellitus and intermediate hyperglycemia: report of a WHO/IDF consultation. Geneva: World Health Organization; 2006.

8. Marler JR, Tilley BC, Lu M, Brott TG, Lyden PC, Grotta JC, Broderick JP, Levine SR, Frankel MP, Horowitz SH, Haley EC Jr, Lewandowski CA, Kwiatkowski TP. Early stroke treatment associated with better outcome: the NINDS rt-PA stroke study. Neurology 2000, 55:1649-1655.

9. De Morais SM, Wilkinson GR, Blaisdell J, Nakamura K, Meyer UA, Goldstein JA: The major genetic detect responsible for the polymorphism of Smephenytoin metabolism in humans. J Biol Chem 1994, 269(22):15419-15422.

10. De Morais SM, Wilkinson CR, Blaisdell J, Meyer UA, Nakamura K, Goldstein $J A$ : Identification of a new genetic defect responsible for the polymorphism of (S)-mephenytoin metabolism in Japanese. Mol Pharmacol 1994, 46(4):594-598.

11. De Morais SM, Goldstein JA, Xie HG, Huang SL, Lu YQ, Xia ZS, Ile N, Zhou $\mathrm{HH}$ : Genetic analysis of the S-mephenytoin polymorphism in a Chinese population. Clin Pharmacol Ther 1995, 58(4):404-411.

12. Halling J, Petersen MS, Damkier P, Nielsen F, Grandjean P, Weihe P, Lundblad MS, Brosen K: Polymorphism of CYP2D6, CYP2C19, CYP2C9 and CYP2C8 in the Faroese population. Eur J Clin Pharmacol 2005, 61(7):491-497.

13. Yin SJ, Ni YB, Wang SM, Wang X, Lou YQ, Zhang GL: Differences in genotype and allele frequency distributions of polymorphic drug metabolizing enzymes CYP2C19 and CYP2D6 in mainland Chinese Mongolian, Hui and Han populations. J Clin Pharm Ther 2012, 37(3):364-369.

14. Ghodke Y, Joshi K, Arya Y, Radkar A, Chiplunkar A, Shintre P, Patwardhan B: Genetic polymorphism of CYP2C19 in Maharashtrian population. Eur J Epidemiol 2007, 22:907-915

15. Sistonen J, Fuselli S, Palo JU, Chauhan N, Padh H, Sajantila A: Pharmacogenetic variation at CYP2C9, CYP2C19 and CYP2D6 at global and microgeographic scales. Pharmacogenet Genomics 2009, 19:170-179.

16. Chen M, Liu XJ, Yan SD, Peng Y, Chai H, Li Q, Wei JF, Xu YN, Huang DJ: Association between cytochrome P450 2C19 polymorphism and clinical outcomes in Chinese patients with coronary artery disease. Atherosclerosis 2012, 220(1):168-171.

17. Mega JL, Close SL, Wiviott SD, Shen L, Hockett RD, Brandt JT, Walker JR, Antman EM, Macias W, Braunwald E, Sabatine MS: Cytochrome P-450 Polymorphisms and Response to Clopidogrel. N Engl J Med 2009, 360(4):354-362.

18. Harmsze AM, van Werkum JW, Bouman HJ, Ruven HJ, Breet NJ, Ten Berg JM, Hackeng CM, Tjoeng MM, Klungel OH, de Boer A, Deneer VH: Besides CYP2C19*2, the variant allele CYP2C9*3 is associated with higher on-clopidogrel platelet reactivity in patients on dual antiplatelet therapy undergoing elective coronary stent implantation. Pharmacogenet Genomics 2010, 20(1):18-25.

19. Lee JB, Lee KA, Lee KY: Cytochrome P450 2C19 polymorphism is associated with reduced clopidogrel response in cerebrovascular disease. Yonsei Med J 2011, 52(5):734-738.

20. Subraja K, Dkhar SA, Priyadharsini R, Ravindra BK, Shewade DG, Satheesh S, Sridhar MG, Narayan SK, Adithan C: Genetic polymorphisms of CYP2C19 influences the response to clopidogrel in ischemic heart disease patients in the South Indian Tamilian population. Eur J Clin Pharmacol 2013, 69(3):415-422.

21. Hwang SJ, Jeong YH, Kim IS, Koh JS, Kang MK, Park Y, Kwak CH, Hwang JY: The cytochrome $2 \mathrm{C} 19 * 2$ and $* 3$ alleles attenuate response to clopidogrel similarly in East Asian patients undergoing elective percutaneous coronary intervention. Thromb Res 2011, 127(1):23-28.

22. Kim IS, Choi BR, Jeong YH, Kwak CH, Kim S: The CYP2C19*2 and CYP2C19*3 polymorphisms are associated with high post-treatment platelet reactivity in Asian patients with acute coronary syndrome. J Thromb Haemost 2009, 7(5):897-899.

23. Lee JM, Park S, Shin DJ, Choi D, Shim CY, Ko YG, Kim JS, Shin ES, Chang CW, Lee JE, Jang Y: Relation of genetic polymorphisms in the cytochrome P450 gene with clopidogrel resistance after drug-eluting stent implantation in Koreans. Am J Cardiol 2009, 104(1):46-51.

doi:10.1186/1471-2350-15-83

Cite this article as: Gu et al:: Association between genetic polymorphisms of cytochrome P450 2C19 and the risk of cerebral ischemic stroke in Chinese. BMC Medical Genetics 2014 15:83.

\section{Submit your next manuscript to BioMed Central and take full advantage of:}

- Convenient online submission

- Thorough peer review

- No space constraints or color figure charges

- Immediate publication on acceptance

- Inclusion in PubMed, CAS, Scopus and Google Scholar

- Research which is freely available for redistribution 